\title{
Right over left ventricular end-diastolic area relevance to predict hemodynamic intolerance of high-frequency oscillatory ventilation in patients with severe ARDS
}

\author{
Lionel Ursulet ${ }^{1}$, Arnaud Roussiaux', Dominique Belcour ${ }^{1}$, Cyril Ferdynus², Bernard-Alex Gauzere'
} David Vandroux ${ }^{1}$ and Julien Jabot ${ }^{1 *}$

\begin{abstract}
Background: High-frequency oscillatory ventilation (HFOV) does not improve the prognosis of ARDS patients despite an improvement in oxygenation. This paradox may partly be explained by HFOV hemodynamic side-effects on right ventricular function. Our goal was to study the link between HFOV and hemodynamic effects and to test if the pre-HFOV right over left ventricular end-diastolic area (RVEDA/LVEDA) ratio, as a simple parameter of afterloadrelated RV dysfunction, could be used to predict HFOV hemodynamic intolerance in patients with severe ARDS.

Methods: Twenty-four patients were studied just before and within $3 \mathrm{~h}$ of HFOV using transthoracic echocardiography and transpulmonary thermodilution.

Results: Before HFOV, the mean $\mathrm{PaO}_{2} / \mathrm{FiO}_{2}$ ratio was $89 \pm 23$. The number of patients with a RVEDA/LVEDA ratio $>0.6$ significantly increased after HFOV [11 (46\%) vs. 17 (71 \%)]. Although HFOV did not significantly decrease the arterial pressure (systolic, diastolic, mean and pulse pressure), it significantly decreased the cardiac index (CI) by $13 \pm 18 \%$ and significantly increased the RVEDA/LVEDA ratio by $14 \pm 11 \%$. A significant correlation was observed between pre-HFOV RVEDA/LVEDA ratio and CI diminution after HFOV $(r=0.78 ; p<0.0001)$. A RVEDA/LVEDA ratio superior to 0.6 resulted in a $\mathrm{Cl}$ decrease $>15 \%$ during HFOV with a sensitivity of $80 \%$ (95\% confidence interval $44-98 \%$ ) and a specificity of $79 \%$ (confidence interval 49-95\%).
\end{abstract}

Conclusion: The RVEDA/LVEDA ratio measured just before HFOV predicts the hemodynamic intolerance of this technique in patients with severe ARDS. A high ratio under CMV raises questions about the use of HFOV in such patients. Trial registration: ClinicalTrials.gov: NCT01167621

Keywords: Acute respiratory distress syndrome, High-frequency oscillatory ventilation, Hemodynamic monitoring, Acute right ventricular dysfunction, Echocardiography, Transpulmonary thermodilution

\section{Background}

In severe acute respiratory distress syndrome (ARDS), alternative therapies are indicated [1] when protective conventional mechanical ventilation (CMV) fails to maintain efficient gas exchange. High-frequency

\footnotetext{
*Correspondence: jabot974@gmail.com

${ }^{1}$ Medical Surgical Intensive Care Unit, Saint Denis University Hospital,

Saint Denis, Reunion Island, France

Full list of author information is available at the end of the article
}

oscillatory ventilation (HFOV) is a non-CMV technique that could improve alveolar recruitment and achieve protective ventilation with the most severe cases of ARDS using very low tidal volume (VT) and relatively high mean airway pressure (mPaw) as a surrogate for positive end-expiratory pressure (PEEP). Previous studies have clearly shown an improvement in oxygenation with HFOV [2] and even suggest a reduction in mortality $[3,4]$ although the level of improvement in oxygenation 
is unpredictable and HFOV can indeed worsen oxygenation in some patients [5]. Alveolar recruitment-and thus improvement in gas exchange-seems to depend on the level of mPaw $[6,7]$ and a high mPaw (around $30 \mathrm{~cm}$ $\mathrm{H}_{2} \mathrm{O}$ ) for a period of several days seems to give the best results [6]. Unfortunately, two large, multicenter, randomized controlled trials recently raised doubts about the safety of HFOV: the first [8] showed no significant effect on 30-day mortality and, troublingly, the second [9] was prematurely discontinued following a nonsignificant but constant increase in mortality at each interim analysis. This paradox-an improvement in oxygenation in most cases on the one hand but no mortality reduction on the other-may partly be explained by the hemodynamic side-effects of HFOV. Indeed, a retrospective study [5] involving 190 patients treated by HFOV reported a high rate of hemodynamic complications (27\%). A study involving only nine patients with high mPaw HFOV showed a decrease in cardiac index (CI), probably due to airway pressure-related preload reduction [10]. Finally, a study involving 16 patients demonstrated that HFOV could worsen right ventricular function [11]. Therefore, our goal was to monitor hemodynamic effects during the first $3 \mathrm{~h}$ with high mPaw HFOV using transthoracic echocardiography (TTE) and transpulmonary thermodilution (TPTD) and to assess if afterload-related RV dysfunction measured just before HFOV like the right over left ventricular end-diastolic area (RVEDA/LVEDA) ratio could predict hemodynamic intolerance during HFOV.

\section{Methods}

\section{Patients}

This observational prospective study was approved by the ethics committee of Bordeaux University Hospital (Comité de Protection des Personnes Sud-Ouest et Outre-Mer III, no. 2010-A00338-31).Written informed consent was obtained from each patient's next of kin.

In our 18-bed intensive care unit (ICU), VMC therapy for ARDS was set according to a standardized protocol for maximal alveolar recruitment: protective CMV consisted of a volume-controlled mode with a VT of $6 \mathrm{~mL} \mathrm{~kg}^{-1}$ of predicted body weight (PBW), maximal PEEP without exceeding a plateau airway pressure of 30 $\mathrm{cm}_{2} \mathrm{O}$ [12], controlled sedation for a Ramsay Score $>5$ [13] followed by continuous infusion of cis-atracurium [14] and systematic use of a heated humidifier and a closed endotracheal suction catheter [15]. All patients were hemodynamically optimized according to TPTD monitoring PiCCO2 (Pulsion Medical Systems, Munich, Germany) and/or TTE monitoring [16, 17].

In our unit, refractory ARDS was defined as follows:
- Life-threatening hypoxemia $\left(\mathrm{PaO}_{2} / \mathrm{FiO}_{2}<70 \mathrm{mmHg}\right)$ at any time during the first $12 \mathrm{~h}$ of $\mathrm{CMV}$ for maximal alveolar recruitment

- When one of more of the following criteria are met after $12 \mathrm{~h}$ of CMV: arterial blood oxygen saturation $<90 \%$ with fraction of inspired oxygen $\left(\mathrm{FiO}_{2}\right)=1 ; \mathrm{PaO}_{2} / \mathrm{FiO}_{2}$ ratio $<120$; hypercapnia $>55 \mathrm{mmHg}$ or $\mathrm{pH}<7.20$ despite a respiratory rate of $35 \mathrm{~min}^{-1}$, plateau airway pressure $>30 \mathrm{~cm} \mathrm{H}_{2} \mathrm{O}$ with a tidal volume of $6 \mathrm{~mL} \mathrm{~kg}^{-1}$ of PBW and a $5 \mathrm{~cm}$ $\mathrm{H}_{2} \mathrm{O}$ minimal PEEP.

When a patient exhibited these criteria for refractory ARDS, rescue therapies were considered (i.e., HFOV, prone positioning [18] or extra-corporeal membrane oxygenation (ECMO) [19]). Patients undergoing HFOV were enrolled in the study from May 2010 to November 2012 if the following criteria were met:

- Refractory ARDS

- HFOV used as an alternative therapy to CMV

- A TPTD device used for hemodynamic monitoring

- Hemodynamic stability during the $10 \mathrm{~min}$ prior to HFOV (mean arterial pressure stable and between 65 and $85 \mathrm{mmHg}$, no CI variation of more than $10 \%$ given by the $\mathrm{PiCCO}_{2}$ beat-to-beat pulse contour analysis, no change in norepinephrine dose).

\section{Exclusion criteria were:}

- Age $<18$ years

- Moribund status

- Contraindications to HFOV (head injury, pneumothorax or persistent air leak despite chest tube insertion)

- Hemodynamic instability before HFOV

- Poor echogenicity preventing appropriate echocardiographic assessment by TTE.

\section{HFOV}

\section{Initial settings and parameter adjustment}

At inclusion, HFOV (3100B SensorMedics ventilator, Yorba Linda, CA, USA) was initially set as follows: $\mathrm{FiO}_{2}$ 1; frequency $6 \mathrm{~Hz}$; bias flow $40 \mathrm{~L} \mathrm{~min}{ }^{-1}$; mPaw $10 \mathrm{~cm}$ $\mathrm{H}_{2} \mathrm{O}$ above the CMV mPAw up to a maximum of $30 \mathrm{~cm}$ $\mathrm{H}_{2} \mathrm{O}$ and pressure amplitude of oscillation $80 \%$. During the 3-h protocol, mPaw and bias flow were not modified; other parameters were adjusted as follows:

- $\mathrm{FiO}_{2}$ adjusted to obtain a $\mathrm{PaO}_{2}$ of $60-85 \mathrm{mmHg}$

- Frequency and pressure amplitude of oscillation adjusted to obtain a $\mathrm{pH}>7.25$ and a $\mathrm{PCO}_{2}<55 \mathrm{mmHg}$ 


\section{HFOV failure criteria}

HFOV was defined as a failure if at least one of the following occurred:

- Oxygen saturation fell below $90 \%$ despite a $\mathrm{FiO}_{2} 1$

- $\mathrm{PaO}_{2} / \mathrm{FiO}_{2}$ ratio $<70$

- Hypercapnia $>55 \mathrm{mmHg}$ and/or $\mathrm{pH}<7.20$ despite a frequency of $3.5 \mathrm{~Hz}$ and pressure amplitude of oscillation of $100 \%$

- Occurrence of a new pneumothorax.

We defined HFOV-associated hemodynamic failure as major hemodynamic instability linked to HFOV: significant arterial hypotension (systolic arterial pressure under $90 \mathrm{mmHg}$ or a decrease $>30 \%$ of initial systolic pressure) and/or CI decrease $>30 \%$.

When HFOV failure was ascertained, CMV was removed leading to the termination of the study and an alternative method of oxygenation (prone positioning or ECMO) was initiated. If systolic arterial pressure was under $90 \mathrm{mmHg}$, the norepinephrine dose was increased during the HFOV-CMV transfer process.

\section{Hemodynamic measurements}

The study began at patient inclusion, i.e., under CMV during a 10-min period before initiation of HFOV, and ended $3 \mathrm{~h}$ later. The different stages of the study were:

- Just before initiation of HFOV (CMVpre)

- Connection to HFOV (HFOV connection)

- After 1 h of HFOV $\left(\mathrm{H}_{1 \text { HFOV }}\right)$

- After 3 h of HFOV $\left(\mathrm{H}_{3 \text { HFOV }}\right)$

In each sequence, heart rate, arterial pressure, catecholamine and sedation dose rates and TTE and TPTD data were recorded.

\section{TTE measurements}

TTE were performed by a single experienced echocardiographer. Images were acquired using an EnVisor Philips HD 11XE (Philips Medical System, Andover, MA, USA) scanner and a $3 \mathrm{MHz}$ transducer. Two-dimensional (2D) imaging examinations were performed in the standard apical four- and two-chamber views (4C- and $2 \mathrm{C}$-views). Tissue harmonic imaging was used to enhance 2D image quality. Left ventricular ejection fraction (LVEF) was measured either by the biplane or monoplane Simpson method [20]. The velocity-time integral in the left ventricular outflow tract (LVOT VTI) was measured using pulsed wave Doppler in the apical five-chamber view. LVEDA and RVEDA were measured in the $4 \mathrm{C}$-view. Echocardiographic patterns of acute cor pulmonale (ACP) associating RVEDA/LVEDA ratio $>0.6$ and systolic septal dyskinesia on a short-axis view were looked for [21]. LV filling parameters were assessed in the $4 \mathrm{C}$-view and using pulsed wave and tissue Doppler imaging in accordance with the current standards [22, 23]. All TTE studies were recorded over three consecutive cardiac cycles independently of the respiratory cycle and averaged. In patients with non-sinus rhythm, measurements were collected over 5-7 heartbeats.

\section{TPTD measurements}

Injection of $15 \mathrm{~mL}$ of cold saline through the central venous line was performed in triplicate, and the values of the different TDTP parameters [CI, stroke volume index (SVI), global end-diastolic index (GEDI) and cardiac function index (CFI)] were averaged [24].

\section{Respiratory measurements}

For each sequence, ventilator settings, respiratory system mechanical parameters, arterial blood gas analysis, extravascular lung water index (ELWI) and pulmonary vascular permeability water index (PVPI) obtained by TPTD were collected $[25,26]$.

\section{Statistical analysis}

Qualitative variables were described in frequencies and proportions. Quantitative variables were described in means and standard deviations. Evolution of hemodynamic and respiratory levels during the study was assessed using a linear mixed model adjusted for time. A first-order autoregressive variance-covariance matrix was specified, to account for the correlated repeated time data. All multiple comparisons were performed using the Scheffe adjustment. The receiver operating characteristics curve was constructed to assess the ability of an RVEDA/LVEDA ratio at inclusion to predict a decrease in CI $>15 \%$ with HFOV. Spearman rank correlation analysis was used to assess the relationship between RVEDA/ LVEDA ratio at inclusion and changes in CI on HFOV. Statistical analysis was performed using the SAS 9.2 software (SAS Institute, Cary, NC, USA). All hypotheses were tested at the 2 -tailed 0.05 significance level.

\section{Results}

Twenty-four patients (7 women and 17 men) were included in the study. None of them had a history of chronic respiratory failure. The mean time between ICUCMV and HFOV was $9 \pm 4 \mathrm{~h}$. Twenty-three patients were still under $\mathrm{HFOV}$ at $\mathrm{H}_{1}$ (one patient was withdrawn for hemodynamic failure), and 19 at $\mathrm{H}_{3}$ (two patients were withdrawn for respiratory failure and two more for hemodynamic failure).

On admission, the Simplified Acute Physiology Score II (SAPS II) and the Sequential Organ Failure Assessment 
(SOFA) were, respectively, $60 \pm 17$ and $12 \pm 3$. Mortality at D28 was $46 \%$. Causes of ARDS were pulmonary for $75 \%$ of patients $(n=18)$ (thirteen cases of infectious pneumonia, four aspiration pneumonia and one drowning accident), and extra-pulmonary for $25 \%$ of patients $(n=6)$. At baseline, 21 patients $(82 \%)$ were receiving norepinephrine and three dobutamine. The respiratory variables during $\mathrm{CMV}$ at baseline are summarized in Table 1.

\section{Hemodynamic parameters \\ Rate and cause of hemodynamic failure}

Hemodynamic failure was reported in three patients (12\%), occurring within the first $90 \mathrm{~min}$ after HFOV. These three patients had an ACP echocardiographic pattern not only during CMV but also after HFOV.

\section{Hemodynamic effects of HFOV}

As shown in Table 2, although HFOV did not significantly decrease arterial pressure (systolic, diastolic, mean and pulse pressure), it significantly decreased CI by $13 \pm 11 \%$ from $3.7 \pm 1.1 \mathrm{~L} \mathrm{~min}^{-1} \mathrm{~m}^{-2}$ at baseline and LVOT VTI by $13 \pm 12 \%$ from $17 \pm 5 \mathrm{~cm}$ at baseline. SVI, GEDI, CFI, LVEF and E/A ratio also significantly decreased, whereas the RVEDA/LVEDA ratio increased by $14 \pm 11 \%$, from

\section{Table 1 Respiratory variables at baseline}

\begin{tabular}{|c|c|}
\hline \multicolumn{2}{|l|}{ Ventilator settings } \\
\hline$V T\left(m L k^{-1}\right.$ PBW $)$ & $5.8 \pm 0.6$ \\
\hline Respiratory rate (cycles min $^{-1}$ ) & $29 \pm 3$ \\
\hline $\operatorname{PEEP}\left(\mathrm{cm} \mathrm{H}_{2} \mathrm{O}\right)$ & $11 \pm 3$ \\
\hline $\mathrm{FiO}_{2}(\%)$ & $97 \pm 9$ \\
\hline \multicolumn{2}{|l|}{ Respiratory-system mechanics } \\
\hline Plateau airway pressure $\left(\mathrm{cm} \mathrm{H}_{2} \mathrm{O}\right)$ & $29 \pm 2$ \\
\hline mPaw $\left(\mathrm{cm} \mathrm{H}_{2} \mathrm{O}\right)$ & $19 \pm 3$ \\
\hline Respiratory system compliance $\left(\mathrm{mL} \mathrm{cm} \mathrm{H}_{2} \mathrm{O}^{-1}\right)$ & $22 \pm 9$ \\
\hline \multicolumn{2}{|l|}{ Results of $A B G$ measurements } \\
\hline $\mathrm{pH}$ & $7.24 \pm 0.14$ \\
\hline $\mathrm{P} /$ F ratio & $89 \pm 23$ \\
\hline $\mathrm{PaO}_{2}(\mathrm{mmHg})$ & $86 \pm 22$ \\
\hline $\mathrm{PaCO}_{2}(\mathrm{mmHg})$ & $53 \pm 15$ \\
\hline Bicarbonate $\left(\mathrm{mmol} \mathrm{L}^{-1}\right)$ & $24 \pm 5$ \\
\hline Base excess $\left(\mathrm{mmol} \mathrm{L}^{-1}\right)$ & $-6 \pm 6$ \\
\hline \multicolumn{2}{|l|}{ TDTP respiratory parameters } \\
\hline ELWI (mL kg ${ }^{-1}$ PBW) & $19 \pm 7$ \\
\hline PVPI & $5.1 \pm 1.7$ \\
\hline
\end{tabular}

Results are given as mean $\pm S D$

$A B G$ arterial blood gas, TPTD transpulmonary thermodilution, $V T$ tidal-volume, $P B W$ predicted body weight, PEEP positive end-expiratory pressure, $\mathrm{FiO}_{2}$ fraction of inspired oxygen, $m$ Paw mean airway pressure, $P / F$ ratio of arterial oxygen concentration to the fraction of inspired oxygen, $\mathrm{PaCO}_{2}$ partial pressure of arterial carbon dioxide, $\mathrm{PaO}_{2}$ partial pressure of arterial oxygen, $\mathrm{ELWI}$ extravascular lung water index, PVPI pulmonary vascular permeability index
$0.61 \pm 0.15$ at baseline. The number of patients with an RVEDA/LVEDA ratio $>0.6$ and with an ACP echocardiographic pattern significantly increased during HFOV [11 (46\%) vs. 17 (71\%) and 5 (21\%) vs. 11 (46\%), respectively]. For each patient, RVEDA/LVEDA ratio on inclusion was compared with the percentage change in TDTP $\mathrm{CI}$ between inclusion and HFOV. When considering these 24 pairs of measurements, a significant inverse correlation was observed $(r=-0.78 ; p<0.0001)$ (Fig. 1). An RVEDA/LVEDA ratio superior to 0.6 predicted a decrease in $\mathrm{CI}>15 \%$ during HFOV with a sensitivity of $80 \%$ (95\% confidence interval 44-98\%) and a specificity of $79 \%$ (confidence interval 49-95\%) (Fig. 2).

\section{Hemodynamic changes during the first $3 h$ of HFOV}

There was no hemodynamic change during the first $3 \mathrm{~h}$ with the exception of E-wave, E/A ratio, RVEDA/LVEDA ratio and numbers of ACP echocardiographic patterns (Table 2).

\section{Therapeutic interventions by the attending physicians}

During the 3-h study, no volume expansion was administered to patients and there was no significant change in doses of catecholamines, sedative drugs or cisatracurium. Therapeutic interventions were carried out only on the three patients with HFOV-associated hemodynamic failure.

\section{Respiratory parameters}

Respiratory parameter changes are summarized in Table 3. The comparison of $\mathrm{PaO}_{2} / \mathrm{FiO}_{2}$ ratios revealed a significant increase of $90 \%$ or more between the HFOV sequences and CMVpre sequence.

At $\mathrm{H}_{1}$ HFOV , the $\mathrm{PaO}_{2} / \mathrm{FiO}_{2}$ ratio increased from the baseline value by more than $100 \%$ for $39 \%$ of patients and by more than $30 \%$ for $61 \%$ of patients.

At $\mathrm{H}_{3} \mathrm{HFOV}$, the $\mathrm{PaO}_{2} / \mathrm{FiO}_{2}$ ratio increased from the baseline value by more than $100 \%$ for $47 \%$ of patients and by more than $30 \%$ for $74 \%$ of patients.

During the study, there was no significant difference between the mean $\mathrm{PaO}_{2} / \mathrm{FiO}_{2}$ ratios of the 18 patients with pulmonary ARDS and the 6 patients with extrapulmonary ARDS $(91 \pm 22$ vs. $83 \pm 27$ at inclusion, $180 \pm 104$ vs. $147 \pm 119$ at $\mathrm{H}_{1}$ and $186 \pm 81$ vs. $158 \pm 131$ at $\mathrm{H}_{3}$, respectively).

\section{Discussion}

To our knowledge, this study is the largest that focuses specifically on hemodynamic changes during HFOV. It confirms the significant CI decrease linked to HFOV. It also suggests that the initial pre-HFOV RVEDA/LVEDA ratio can predict the hemodynamic intolerance induced by HFOV. 
Table 2 Evolution of the hemodynamic characteristics during the study

\begin{tabular}{|c|c|c|c|c|}
\hline & $\mathrm{CMV}_{\text {pre }}$ & HFOV connection & $\mathrm{H}_{1 \text { HFOV }}$ & $\mathrm{H}_{3 \mathrm{HFOV}}$ \\
\hline Concerned patients number & 24 & 24 & 23 & 19 \\
\hline Heart rate (beats/min) & $102 \pm 22$ & $102 \pm 23$ & $102 \pm 23$ & $102 \pm 24$ \\
\hline Systolic arterial pressure $(\mathrm{mmHg})$ & $120 \pm 18$ & $119 \pm 23$ & $119 \pm 19$ & $116 \pm 17$ \\
\hline Diastolic arterial pressure $(\mathrm{mmHg})$ & $62 \pm 11$ & $63 \pm 12$ & $65 \pm 11$ & $62 \pm 11$ \\
\hline Mean arterial pressure $(\mathrm{mmHg})$ & $81 \pm 11$ & $81 \pm 13$ & $80 \pm 14$ & $80 \pm 12$ \\
\hline Pulse pressure $(\mathrm{mmHg})$ & $57 \pm 13$ & $56 \pm 17$ & $54 \pm 17$ & $54 \pm 13$ \\
\hline Cardiac index $\left(\mathrm{L} \mathrm{min}^{-1} \mathrm{~m}^{-2}\right)$ (TPTD) & $3.7 \pm 1.1^{b, c, d}$ & $3.3 \pm 1.3^{\mathrm{a}}$ & $3.3 \pm 1.2^{\mathrm{a}}$ & $3.1 \pm 1.1^{\mathrm{a}}$ \\
\hline $\mathrm{SVI}\left(\mathrm{mL} \mathrm{min}^{-1} \mathrm{~m}^{-2}\right)$ (TPTD) & $36 \pm 11^{b, c, d}$ & $33 \pm 14^{\mathrm{a}}$ & $33 \pm 14^{\mathrm{a}}$ & $32 \pm 14^{\mathrm{a}}$ \\
\hline GEDI (mL $\left.\min ^{-1} \mathrm{~m}^{-2}\right)$ (TPTD) & $680 \pm 140^{b, c, d}$ & $634 \pm 134^{\mathrm{a}}$ & $646 \pm 126^{\mathrm{a}}$ & $625 \pm 112^{\mathrm{a}}$ \\
\hline CFI $\left(\mathrm{min}^{-1}\right)$ (TPTD) & $5.5 \pm 1.8^{b, c, d}$ & $5.2 \pm 1.9^{\mathrm{a}}$ & $5.0 \pm 1.8^{\mathrm{a}}$ & $5.0 \pm 1.5^{\mathrm{a}}$ \\
\hline LVEF (\%) (TTE) & $53 \pm 16^{b, c, d}$ & $50 \pm 17^{\mathrm{a}}$ & $49 \pm 15^{\mathrm{a}}$ & $49 \pm 13^{\mathrm{a}}$ \\
\hline RVEDA/LVEDA ratio (TTE) & $0.61 \pm 0.15^{b, c, d}$ & $0.70 \pm 0.18^{\mathrm{a}}$ & $0.72 \pm 0.18^{\mathrm{a}}$ & $0.67 \pm 0.14^{\mathrm{a}}$ \\
\hline RVEDA/LVEDA ratio >0.6 $[n(\%)]$ & $11(46)^{b, c}$ & $17(71)^{\mathrm{a}, \mathrm{d}}$ & $17(74)^{\mathrm{a}, \mathrm{d}}$ & $10(53)^{b, c}$ \\
\hline ACP echocardiographic pattern $[n(\%)]$ & $5(21)^{b, c}$ & $11(46)^{\mathrm{a}, \mathrm{d}}$ & $10(43)^{\mathrm{a}, \mathrm{d}}$ & $6(32)^{b, c}$ \\
\hline LVOT VTI (cm) (TTE) & $17 \pm 5^{b, c, d}$ & $14 \pm 5^{\mathrm{a}}$ & $14 \pm 5^{\mathrm{a}}$ & $14 \pm 5^{\mathrm{a}}$ \\
\hline E-wave $\left(\mathrm{cm} \mathrm{s}^{-1}\right)(T T E)$ & $90 \pm 23^{c}$ & $86 \pm 20^{c}$ & $80 \pm 21^{a, b, d}$ & $91 \pm 22^{c}$ \\
\hline A-wave $\left(\mathrm{cm} \mathrm{s}^{-1}\right)$ (TTE) & $57 \pm 16$ & $58 \pm 12$ & $54 \pm 12$ & $57 \pm 15$ \\
\hline $\mathrm{E}^{\prime}\left(\mathrm{cm} \mathrm{s}^{-1}\right)(\mathrm{TTE})$ & $14 \pm 5$ & $14 \pm 5$ & $14 \pm 4$ & $15 \pm 5$ \\
\hline DTE (ms) (TTE) & $207 \pm 51$ & $204 \pm 44$ & $213 \pm 38$ & $205 \pm 46$ \\
\hline E/A (TTE) & $1.8 \pm 0.5^{b, c}$ & $1.6 \pm 0.6^{a}$ & $1.6 \pm 0.5^{\mathrm{a}}$ & $1.8 \pm 0.7^{b, c}$ \\
\hline E/E' (TTE) & $8.3 \pm 2.9$ & $8.4 \pm 2.9$ & $7.4 \pm 3.6$ & $8.0 \pm 3.0$ \\
\hline Norepinephrine $\left(\mu \mathrm{g} \mathrm{kg}^{-1} \mathrm{~min}^{-1}\right)$ & $0.59 \pm 0.78$ & $0.59 \pm 0.78$ & $0.58 \pm 0.78$ & $0.53 \pm 0.69$ \\
\hline
\end{tabular}

Results are given as mean \pm SD

CMV conventional mechanical ventilation, HFOV high frequency oscillation ventilation, TPTD transpulmonary thermodilution, SVI stroke volume index, GEDI global end diastolic index, CFI cardiac function index, LVEF left ventricular ejection fraction, TTE transthoracic echocardiography, LVEDA left ventricular end diastolic area, RVEDA right ventricular end diastolic area, LVOTVTI velocity-time integral in the left ventricular outflow tract, DTE E-wave deceleration time

a $p<0.05$ for all data as compared to CMVpre

b $p<0.05$ for all data as compared to HFOV Connection

c $p<0.05$ for all data as compared to $\mathrm{H}_{1}$ HFOV

d $p<0.05$ for all data as compared to $\mathrm{H}_{3} \mathrm{HFOV}$

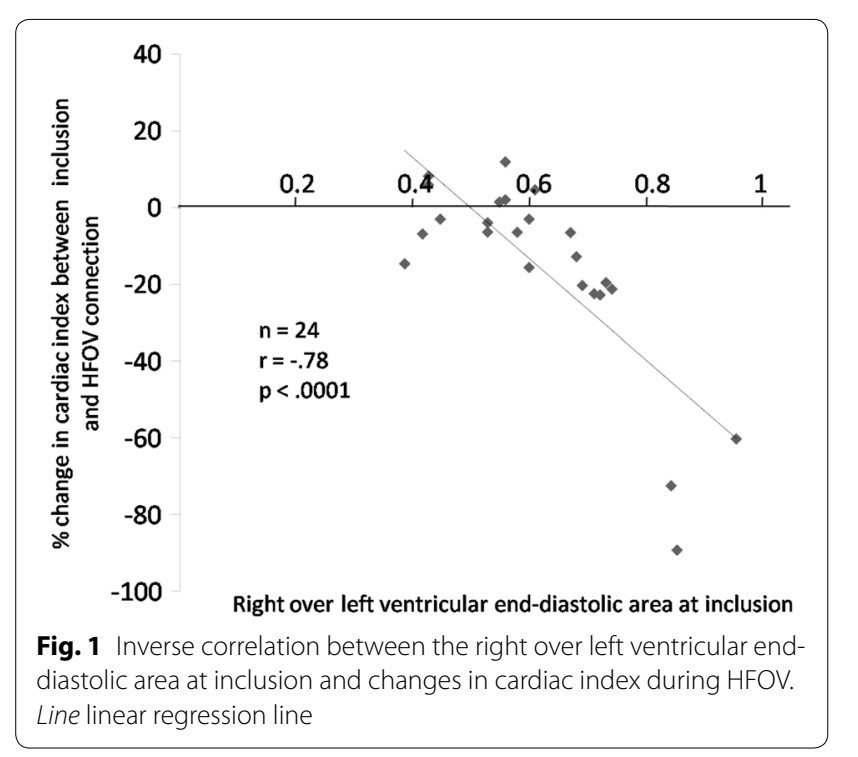

Although right heart dysfunction is a commonly reported side-effect of ARDS protective ventilation [27], only two prospective studies have specifically focused on the hemodynamic effects of HFOV, with both transesophageal echocardiography (TEE) and right heart catheterization monitoring. David et al. reported a clinically significant decrease in CI and SVI thought to be related to a preload decrease [10]. Guervilly et al. described a right ventricular dysfunction in HFOV proportional to the mPaw setting level [11].

Our results are in accordance with those two studies, since HFOV led to a $13 \%$ decrease in $\mathrm{CI}$ and to a $14 \%$ increase of RVEDA/LVEDA. The proportion of patients with a ratio above 0.6 (46\%) is comparable with that reported by Guervilly et al. (56 \%) [11].

The initial pre-HFOV RVEDA/LVEDA ratio is a good predictive factor of HFOV hemodynamic intolerance, as shown by the strong correlation of $78 \%\left(r^{2}=0.61\right)$ 


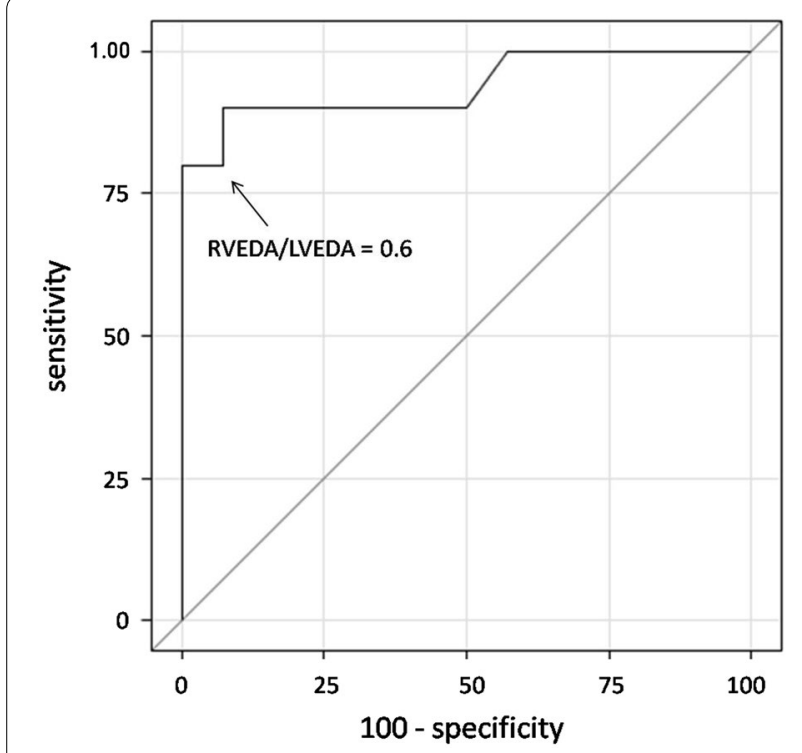

Fig. 2 Receiver operating characteristic curve showing the ability of the right over left ventricular end-diastolic area at inclusion to detect a cardiac index decrease $\geq 15 \%$ during HFOV. RVEDA right ventricular end diastolic area, LVEDA left ventricular end diastolic area

between the pre-HFOV ratio and the CI decrease induced by HFOV and the sensitivity ( $80 \%)$ and specificity (79\%) values found to predict a decrease in $15 \%$ CI by a CMV pre-HFOV RVEDA/LVEDA superior to 0.6 .
Such results underline the value of performing an echocardiography before HFOV to assess the RVEDA/LVEDA ratio and the risk of right ventricular dysfunction. In our study, the exact pathophysiology of right ventricular dysfunction cannot be explained given the lack of pulmonary vascular resistance monitoring.

Although our definition of refractory ARDS is neither published nor consensual, these patients had severe ARDS after $12 \mathrm{~h}$ of CMV maximum alveolar recruitment with a mean $\mathrm{PaO}_{2} / \mathrm{FiO}_{2}$ ratio of $89 \pm 23$. This new practice of delaying ARDS severity ranking is of key importance as it precludes inclusion of initially severe ARDS patients showing rapid improvement with CMV once set to maximal alveolar recruitment. Although our study was designed before the new Berlin definition for ARDS [28], its HFOV utilization is very close to that proposed by experts [29]. The early and very brief use of HFOV for $3 \mathrm{~h}$ for severe ARDS patients improved oxygenation in $66 \%$ of cases. These data are consistent with a recent retrospective study [30] in which the early response to HFOV (an improvement of more than $38 \%$ in the $\mathrm{PaO}_{2} /$ $\mathrm{FiO}_{2}$ ratio) was identified as a predictor for survival at day 30 . Therefore, HFOV could be used in the future as a recruitment technique, possibly applied sequentially as for prone positioning. This new approach is currently being studied in our ICU.

It must be said that the two recently published large randomized controlled trials, OSCILLATE [9] and

Table 3 Evolution of the respiratory and gazometric parameters during the study

\begin{tabular}{|c|c|c|c|c|}
\hline & $\mathrm{CMV}_{\text {pre }}$ & HFOV connection & $\mathrm{H}_{1 \text { HFOV }}$ & $\mathrm{H}_{3 \text { HFOV }}$ \\
\hline Concerned patients number & 24 & 24 & 23 & 19 \\
\hline mPaw $\left(\mathrm{cm} \mathrm{H}_{2} \mathrm{O}\right)$ & $19 \pm 3^{b, c, d}$ & $29 \pm 1^{a}$ & $28 \pm 1^{a}$ & $29 \pm 1^{a}$ \\
\hline Frequency $(\mathrm{Hz})$ & NA & $6.0 \pm 0.0^{d}$ & $6.0 \pm 0.0^{d}$ & $5.2 \pm 1.3^{b, c}$ \\
\hline Amplitude $\left(\mathrm{cm} \mathrm{H}_{2} \mathrm{O}\right)$ & NA & $88 \pm 13$ & $86 \pm 12$ & $85 \pm 12$ \\
\hline Pressure amplitude of oscillation (\%) & NA & $80 \pm 0$ & $79 \pm 4$ & $79 \pm 5$ \\
\hline $\mathrm{pH}$ & $7.24 \pm 0.14^{d}$ & NA & $7.25 \pm 0.16$ & $7.30 \pm 0.17^{\mathrm{a}}$ \\
\hline $\mathrm{PaCO}_{2}(\mathrm{mmHg})$ & $53 \pm 15^{d}$ & NA & $49 \pm 19^{a}$ & $47 \pm 15^{\mathrm{a}}$ \\
\hline Bicarbonate $\left(\mathrm{mmol} \mathrm{L}^{-1}\right)$ & $24 \pm 5$ & NA & $23 \pm 6$ & $24 \pm 4$ \\
\hline Base excess $\left(\mathrm{mmol} \mathrm{L}^{-1}\right)$ & $-6 \pm 6^{d}$ & NA & $-6 \pm 7^{d}$ & $-4 \pm 5^{a, c}$ \\
\hline $\mathrm{P} /$ F ratio & $89 \pm 23^{c, d}$ & NA & $171 \pm 106^{\mathrm{a}}$ & $177 \pm 96^{\mathrm{a}}$ \\
\hline $\mathrm{Ol}$ & $26 \pm 8^{d}$ & NA & $26 \pm 17^{d}$ & $23 \pm 15^{a, c}$ \\
\hline ELWI (mL/kg PBW) & $19 \pm 7$ & $19 \pm 7$ & $19 \pm 7$ & $17 \pm 6$ \\
\hline PVPI & $5.1 \pm 1.7$ & $5.2 \pm 1.8$ & $5.1 \pm 1.5$ & $5.1 \pm 1.7$ \\
\hline
\end{tabular}

Results are given as mean \pm SD

$C M V$ conventional mechanical ventilation, $H F O V$ high frequency oscillation ventilation, $m P a w$ mean airway pressure, $F i O_{2}$ fraction of inspired oxygen, $P / F$ ratio of arterial oxygen concentration to the fraction of inspired oxygen, $\mathrm{Ol}$ oxygenation index calculated as (mean airway $\left.\mathrm{pressure} \times \mathrm{FiO}_{2}\right) / \mathrm{PaO} \mathrm{O}_{2}$, $\mathrm{ELWI}$ extravascular lung water index, $P B W$ predicted body weight, $P V P I$ pulmonary vascular permeability index

a $p<0.05$ for all data as compared to $\mathrm{CMV}_{\text {pre }}$

b $p<0.05$ for all data as compared to HFOV connection

c $p<0.05$ for all data as compared to $\mathrm{H}_{1} \mathrm{HFOV}$

d $p<0.05$ for all data as compared to $\mathrm{H}_{3 \mathrm{HFOV}}$ 
OSCAR [8] comparing HFOV with a conventional lungprotective ventilation, casted doubt over HFOV, suggesting no benefit or even a worse outcome on adults with HFOV with early moderate to severe ARDS. But despite strong compliance with current recommendations of protective ventilation from the ARDS network [31] and prompt initiation of HFOV in these two studies, randomization was performed on patients with moderate to severe ARDS $\left(\mathrm{PaO}_{2} / \mathrm{FiO}_{2}<200\right)$, not severe ARDS patients only. Furthermore, the randomization was conducted regardless of early clinical evolution under CMV and the use of muscle relaxants was practitioner dependant. In the OSCILLATE study [9], the use of very high mPaw, without ruling out risk of potential hemodynamic failure, may have led to an excess mortality in the HFOV arm of this study. These two studies have given rise to three recent meta-analyses including 6 RCTs for 1608 patients [32], 5 RCTs for 1580 patients [33] and 7 RCTs for 1759 patients [34] without confirming better survival or higher mortality with HFOV.

Our study has several limitations. Its observational design with non-consecutive patients could engender a selection bias. The study population is small given the monocentric screening and the stringent inclusion criteria. Even if only a single experienced operator performed TTE, a post hoc analysis by an independent expert could have confirmed the hemodynamic data obtained by blinded practitioners. Similarly, data were obtained by TTE and not TEE, which, in the context of HFOV, could cast doubts on the accuracy of the results. Yet, TTE-obtained data are consistent with those found by TPTD (e.g., LVOT VTI and TPTD CI both decreased by $13 \%$ on HFOV) and comparable to those obtained by Guervilly et al. with TEE [11]. Another limitation of the study is the lack of assessment of a potential preload decrease during HFOV. The only way to test this would have been a comparison of the passive leg raising results at inclusion and during HFOV since pulse pressure variation, stroke volume variation, vena cava variations and tele-expiratory occlusion test cannot be used with HFOV. Unfortunately, this test is very difficult to implement with HFOV and would have slowed and complicated the protocol. Lastly, it is unfortunate that we could not compare TTE data with those obtained by a pulmonary artery catheter (PAC) to better assess right ventricular function. However, our study was strictly observational and we routinely use TPTD and not PAC for monitoring patients with severe ARDS. This enables us to better assess the risk/benefit ratio of volume expansion based on ELWI and PVPI rather than on pulmonary capillary pressure $[35,36]$. In this context, we considered it unethical to insert a PAC in addition to a TPTD device only for the purpose of the study.

\section{Conclusion}

This study suggests that the RVEDA/LVEDA ratio measured just before HFOV is a predictor of the hemodynamic intolerance of this technique in patients with severe ARDS. A high value of this ratio observed under CMV should question the use of HFOV in such patients.

\begin{abstract}
Abbreviations
ARDS: acute respiratory distress syndrome; CMV: conventional mechanical ventilation; HFOV: high-frequency oscillatory ventilation; MPaw: mean airway pressure; $\mathrm{Cl}$ : cardiac index; TTE: transthoracic echocardiography; TPTD: transpulmonary thermodilution; RVEDA/LVEDA: right over left ventricular end-diastolic area; ICU: intensive care unit; PBW: predicted body weight; PEEP: positive end-expiratory pressure; 2D: two dimensional; 2C-view: two-chamber view; 4C-view: four-chamber view; LVEF: left ventricular ejection fraction; LVOT VTI: velocity-time integral in the left ventricular outflow tract; ACP: acute cor pulmonale; ELWI: extravascular lung water index; PVPI: pulmonary vascular permeability water index; SVI: stroke volume index; GEDI: global end-diastolic index; CFI: cardiac function index; SAPS II: Simplified Acute Physiology Score II; SOFA: sequential organ failure assessment; PAC: pulmonary artery catheter.
\end{abstract}

\section{Authors' contributions}

LU collected the data, participated in the study design and helped to draft the manuscript. AR collected the data and helped to draft the manuscript. DB collected the data. CF performed the statistical analysis. BAG helped to draft the manuscript. DV participated in the study design and helped to draft the manuscript. JJ collected the data, performed all the TTEs, conceived the study, participated in its design and coordination and helped to draft the manuscript. All authors read and approved the final manuscript.

\section{Author details}

${ }^{1}$ Medical Surgical Intensive Care Unit, Saint Denis University Hospital, Saint Denis, Reunion Island, France. ${ }^{2}$ Methodological Support and Biostatistics Unit, Saint Denis University Hospital, Saint Denis, Reunion Island, France.

\section{Acknowledgements}

We thank Didier Drouet ${ }^{\dagger}$ for his help during the conception of the study and Fidéline Filleul from the methodological support unit of the Saint Denis University Hospital for her help during the request for authorization by the Ethics Committee.

\section{Compliance with ethical guidelines}

\section{Competing interests}

The authors declare that they have no competing interests.

Received: 15 May 2015 Accepted: 8 September 2015

Published online: 17 September 2015

\section{References}

1. Ferguson ND, Fan E, Camporota L, Antonelli M, Anzueto A, Beale R, et al. The Berlin definition of ARDS: an expanded rationale, justification, and supplementary material. Intensive Care Med. 2012;38:1573-82. doi:10.1007/s00134-012-2682-1.

2. Niwa T, Hasegawa R, Ryuge M, Kawase M, Kondoh Y, Taniguchi H. Benefits and risks associated with the R100 high frequency oscillatory ventilator for patients with severe hypoxaemic respiratory failure. Anaesth Intensive Care. 2011;39:1111-9.

3. Mentzelopoulos SD, Malachias S, Zintzaras E, Kokkoris S, Zakynthinos E, Makris D, et al. Intermittent recruitment with high-frequency oscillation/ tracheal gas insufflation in acute respiratory distress syndrome. Eur Respir J. 2012;39:635-47. doi:10.1183/09031936.00158810.

4. Sud S, Sud M, Friedrich JO, Meade MO, Ferguson ND, Wunsch H, et al. High frequency oscillation in patients with acute lung injury and acute 
respiratory distress syndrome (ARDS): systematic review and meta-analysis. BMJ. 2010;340:c2327.

5. Adhikari NKJ, Bashir A, Lamontagne F, Mehta S, Ferguson ND, Zhou Q, et al. High-frequency oscillation in adults: a utilization review. Crit Care Med. 2011;39:2631-44. doi:10.1097/CCM.0b013e318226675e.

6. Derdak S, Mehta S, Stewart TE, Smith T, Rogers M, Buchman TG, et al. High-frequency oscillatory ventilation for acute respiratory distress syndrome in adults: a randomized, controlled trial. Am J Respir Crit Care Med. 2002;166:801-8. doi:10.1164/rccm.2108052.

7. Papazian L, Gainnier M, Marin V, Donati S, Arnal J-M, Demory D, et al. Comparison of prone positioning and high-frequency oscillatory ventilation in patients with acute respiratory distress syndrome. Crit Care Med. 2005;33:2162-71.

8. Young D, Lamb SE, Shah S, MacKenzie I, Tunnicliffe W, Lall R, et al. Highfrequency oscillation for acute respiratory distress syndrome. N Engl J Med. 2013;368:806-13. doi:10.1056/NEJMoa1215716.

9. Ferguson ND, Cook DJ, Guyatt GH, Mehta S, Hand L, Austin P, et al. Highfrequency oscillation in early acute respiratory distress syndrome. $N$ Engl J Med. 2013;368:795-805. doi:10.1056/NEJMoa1215554.

10. David M, von Bardeleben RS, Weiler N, Markstaller K, Scholz A, Karmrodt J, et al. Cardiac function and haemodynamics during transition to highfrequency oscillatory ventilation. Eur J Anaesthesiol. 2004;21:944-52.

11. Guervilly C, Forel J-M, Hraiech S, Demory D, Allardet-Servent J, Adda M, et al. Right ventricular function during high-frequency oscillatory ventilation in adults with acute respiratory distress syndrome. Crit Care Med. 2012:40:1539-45. doi:10.1097/CCM.0b013e3182451b4a.

12. Mercat A, Richard J-CM, Vielle B, Jaber S, Osman D, Diehl J-L, et al. Positive end-expiratory pressure setting in adults with acute lung injury and acute respiratory distress syndrome: a randomized controlled trial. JAMA. 2008;299:646-55. doi:10.1001/jama.299.6.646.

13. Van Dishoeck A-M, van der Hooft T, Simoons ML, van der Ent M, Scholte OP, Reimer WJM. Reliable assessment of sedation level in routine clinical practice by adding an instruction to the Ramsay Scale. Eur J Cardiovasc Nurs. 2009;8:125-8. doi:10.1016/j.ejcnurse.2008.10.004.

14. Papazian L, Forel J-M, Gacouin A, Penot-Ragon C, Perrin G, Loundou A, et al. Neuromuscular blockers in early acute respiratory distress syndrome. N Engl J Med. 2010;363:1107-16. doi:10.1056/NEJMoa1005372.

15. Morán I, Bellapart J, Vari A, Mancebo J. Heat and moisture exchangers and heated humidifiers in acute lung injury/acute respiratory distress syndrome patients. Effects on respiratory mechanics and gas exchange. Intensive Care Med. 2006;32:524-31. doi:10.1007/s00134-006-0073-1.

16. Allyn J, Allou N, Dib M, Tashk P, Desmard M, Dufour G, et al. Echocardiography to predict tolerance to negative fluid balance in acute respiratory distress syndrome/acute lung injury. J Crit Care. 2013;28:1006-10. doi:10.1016/j.jcrc.2013.07.044.

17. Isakow W, Schuster DP. Extravascular lung water measurements and hemodynamic monitoring in the critically ill: bedside alternatives to the pulmonary artery catheter. Am J Physiol Lung Cell Mol Physiol. 2006;291:L1118-31. doi:10.1152/ajplung.00277.2006.

18. Guérin C, Reignier J, Richard J-C, Beuret P, Gacouin A, Boulain T, et al. Prone positioning in severe acute respiratory distress syndrome. N Engl J Med. 2013;368:2159-68. doi:10.1056/NEJMoa1214103.

19. Richard C, Argaud L, Blet A, Boulain T, Contentin L, Dechartres A, et al. Extracorporeal life support for patients with acute respiratory distress syndrome: report of a Consensus Conference. Ann Intensive Care. 2014;4:15. doi:10.1186/2110-5820-4-15.

20. Lang RM, Bierig M, Devereux RB, Flachskampf FA, Foster E, Pellikka PA, et al. Recommendations for chamber quantification: a report from the American Society of Echocardiography's Guidelines and Standards Committee and the Chamber Quantification Writing Group, developed in conjunction with the European Association of Echocardiograph. J Am Soc Echocardiogr. 2005;18:1440-63. doi:10.1016/j.echo.2005.10.005.

21. Vieillard-Baron A, Schmitt JM, Augarde R, Fellahi JL, Prin S, Page B, et al. Acute cor pulmonale in acute respiratory distress syndrome submitted to protective ventilation: incidence, clinical implications, and prognosis. Crit Care Med. 2001;29:1551-5. doi:10.1097/00003246-200108000-00009.
22. Nagueh SF, Appleton CP, Gillebert TC, Marino PN, Oh JK, Smiseth OA, et al. Recommendations for the evaluation of left ventricular diastolic function by echocardiography. Eur J Echocardiogr. 2009;10:165-93. doi:10.1093/ ejechocard/jep007.

23. Paulus WJ, Tschöpe C, Sanderson JE, Rusconi C, Flachskampf FA, Rademakers FE, et al. How to diagnose diastolic heart failure: a consensus statement on the diagnosis of heart failure with normal left ventricular ejection fraction by the Heart Failure and Echocardiography Associations of the European Society of Cardiology. Eur Heart J. 2007;28:2539-50. doi:10.1093/eurheartj/ehm037.

24. Sakka SG, Reuter DA, Perel A. The transpulmonary thermodilution technique. J Clin Monit Comput. 2012;26:347-53. doi:10.1007/ s10877-012-9378-5.

25. Sakka SG, Rühl CC, Pfeiffer UJ, Beale R, McLuckie A, Reinhart K, et al. Assessment of cardiac preload and extravascular lung water by single transpulmonary thermodilution. Intensive Care Med. 2000;26:180-7.

26. Monnet X, Anguel N, Osman D, Hamzaoui O, Richard C, Teboul J-L. Assessing pulmonary permeability by transpulmonary thermodilution allows differentiation of hydrostatic pulmonary edema from ALI/ARDS Intensive Care Med. 2007;33:448-53. doi:10.1007/s00134-006-0498-6.

27. Vieillard-Baron A, Price LC, Matthay MA. Acute cor pulmonale in ARDS. Intensive Care Med. 2013;39:1836-8. doi:10.1007/s00134-013-3045-2.

28. Ranieri VM, Rubenfeld GD, Thompson BT, Ferguson ND, Caldwell E, Fan $\mathrm{E}$, et al. Acute respiratory distress syndrome: the Berlin definition. JAMA. 2012;307:2526-33. doi:10.1001/jama.2012.5669

29. Ferguson ND, Fan E, Camporota L, Antonelli M, Anzueto A, Beale R, et al. The Berlin definition of ARDS: an expanded rationale, justification, and supplementary material. Intensive Care Med. 2012;38:1573-82. doi:10.1007/s00134-012-2682-1.

30. Camporota L, Sherry T, Smith J, Lei K, McLuckie A, Beale R. Physiological predictors of survival during high-frequency oscillatory ventilation in adults with acute respiratory distress syndrome. Crit Care. 2013;17:R40. doi:10.1186/cc12550.

31. Ventilation with lower tidal volumes as compared with traditional tidal volumes for acute lung injury and the acute respiratory distress syndrome. The acute respiratory distress syndrome network. N Engl J Med. 2000;342:1301-1308. doi:10.1056/NEJM200005043421801.

32. Gu X-L, Wu G-N, Yao Y-W, Shi D-H, Song Y. In adult acute respiratory distress syndrome patients, is high-frequency oscillatory ventilation more effective and safer than conventional protective ventilation? A meta-analysis of randomized controlled trials. Crit Care. 2014;18:R111. doi:10.1186/cc13900

33. Huang C-T, Lin H-H, Ruan S-Y, Lee M-S, Tsai Y-J, Yu C-J. Efficacy and adverse events of high frequency oscillatory ventilation in adult patients with acute respiratory distress syndrome: a meta-analysis. Crit Care. 2014;18:R102. doi:10.1186/cc13880.

34. Maitra S, Bhattacharjee S, Khanna P, Baidya DK. High-frequency ventilation does not provide mortality benefit in comparison with conventional lung-protective ventilation in acute respiratory distress syndrome: a meta-analysis of the randomized controlled trials. Anesthesiology. 2014; doi:10.1097/ALN.0000000000000306.

35. Kushimoto S, Taira Y, Kitazawa Y, Okuchi K, Sakamoto T, Ishikura H, et al. The clinical usefulness of extravascular lung water and pulmonary vascular permeability index to diagnose and characterize pulmonary edema: a prospective multicenter study on the quantitative differential diagnostic definition for acute lung injury/acute. Crit Care. 2012;16:R232. doi:10.1186/cc11898.

36. Tagami T, Nakamura T, Kushimoto S, Tosa R, Watanabe A, Kaneko T, et al. Early-phase changes of extravascular lung water index as a prognostic indicator in acute respiratory distress syndrome patients. Ann Intensive Care. 2014;4:27. doi:10.1186/s13613-014-0027-7. 